NBER TECHNICAL WORKING PAPER SERIES

\begin{abstract}
INSTRUMENTAL VARIABLES ESTIMATION OF AVERAGE TREATMENT EFFECTS IN ECONOMETRICS AND EPIDEMIOLOGY
\end{abstract}

Joshua D. Angrist

Technical Working Paper No. 115

NATIONAL BUREAU OF ECONOMIC RESEARCH

1050 Massachusetts Avenue

Cambridge, MA 02138

November 1991

The author thanks the Harvard Institute for Economic Research and the National Science Foundation for Einancial support, and Tom Newman and Norman Hearst for comments and data. Thanks also go to Guido Imbens, Whitney Newey, and participants in the Harvard-MIT econometrics workshop for helpful suggestions and comments, to Bill Greene for help with software, and to Gary Chamberlain and Jamie Robins for a number of particularly helpful discussions. Bill Rodgers provided expert research assistance. This paper is part of NBER's research program in Labor studies. Any opinions expressed are those of the author and not those of the National Bureau of Economic Research. 
NBER Technical Working Paper \#115 November 1991

\title{
INSTRUMENTAL VARIABLES ESTIMATION OF AVERAGE TREATMENT EFFECTS IN ECONOMETRICS AND EPIDEMIOLOGY
}

\begin{abstract}
The average effect of intervention or treatment is a parameter of interest in both epidemiology and econometrics. A key difference between applications in the two fields is that epidemiologic research is more likely to involve qualitative outcomes and nonlinear models. An example is the recent use of the Vietnam era draft lottery to construct estimates of the effect of Vietnam era military service on civilian mortality. In this paper. I present necessary and sufficient conditions for linear instrumental variables techniques to consistently estimate average treatment effects in qualitative or other nonlinear models. Most latent index models commonly applied to qualitative outcomes in econometrics fail to satisfy these conditions, and monte carlo evidence on the bias of instrumental estimates of the average treatment effect in a bivariate probit model is presented. The evidence suggests that linear instrumental variables estimators perform nearly as well as the correctly specified maximum likelihood estimator, especially in large samples. Linear instrumental variables and the normal maximum likelihood estimator are also remarkably robust to non-normality.
\end{abstract}

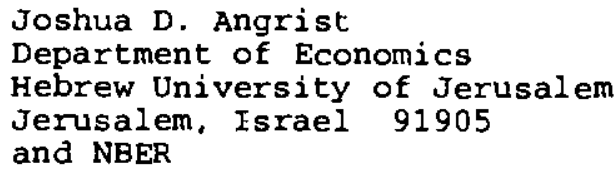


The difference in civilian mortality experience between World War Two veterans and nonveterans is a classic example of the confounding lmpact of selection on estimates of treatment effects. The fact that World War Two veterans have lower mortality than nonveterans the same age is usually attributed to the military screening process (Seltzer and Jablon 1974) and not to any beneficlal effects of wartime service. Recently, Alan Krueger and I (Angrist and Krueger 1989) have shown that the higher earnings enjoyed by veterans from World War Two cohorts are also an artifact of selection bias. Using the fact that some World War Two veterans were drafted according to a sequence determined by day of birth, we construct Instrumental Variables (IV) estimates of the effects of World War Two veteran status on eamings that are free of selection bias. These estimates show that World War Two veterans probably earn less than they would have if they had not served in the milltary.

Whenever some covarlates related to both an outcome of Interest and the probability of treatment are unobserved or unaccounted for, the likelthood of selection blas renders inferences based on simple comparisons Invalid. In such cases, IV estimation provides a powerful and flexible method of correcting for omitted variables blas. IV estimates are constructed by comparing the outcomes of groups with different values of an (Instrumental) variable that is related to the outcome of interest solely by virtue of correlation with the probability of treatment. An 1mportant recent example of this approach in epidemlology is the work by Hearst, Newman, and Hulley (1986) on the effects of Vietnam Era military service on clvilian mortality. Although vietnam era veteran status is a consequence of both self-selection and milltary screening, Hearst, Newman and Hulley use the draft lottery to construct IV estimates of the effects of Vietnam 
era service that are free of selection blas. Similarly, I have used the Vletnam era draft lottery (Angrist 1990) to estimate the effects of Vietnam era service on civilian earnings.

In econometrics, most applications of IV estimators involve linear models with continuous outcome variables. Applications in epidemiology, such as the smoking study by Permute and Hebel 1989), can also 1nvolve inear models. But applications such as the Vietnam mortality example and Hearst, Buehler, Newman, and Rutherford's (1990) recent study of intravenous drug use among veterans involve $11 \mathrm{~m} 1$ ted dependent variables that are usually fitted using nonlinear models. This paper discusses the use of linear IV techniques to estimate average treatment effects in such nonlinear models.

Linear IV techniques are attractive for several reasons. First, the source of 1dentifying information is transparent to the consumer of applied research: the instruments generate a natural experiment that assigns treatment in a manner independent of unobserved covariates. Second, the linear IV estimator does not require observations on Individuals; sample covariances are sufficlent statistics for estimates of regression parameters. In some applications, (e.g., Angrist and Krueger 1990a, and below), these sample moments are actually taken from different data sets. Third, consistency of IV estimates does not require consistent estimation of the reduced form for endogenous regressors (Kelejlan 1971). Th1s is particularly important in an evaluation context, where the reduced form for an endogenous dummy variable is also likely to be nonlinear.

The paper 15 organized as follows. To further motivate the use of IV In nonlinear qualitative response models, Section 1 presents an 1llustration using the Hearst, Newman, and Hulley data on Vietnam era 
military service and mortality. Section 2 defines the average treatment effect for a class of nonlinear models. Section 3 presents necessary and sufficient conditions for IInear IV moment conditions to Identify average treatment effects. Section 4 discusses the asymptotic bias of IV estimates of average treatment effects when the identification conditions fall to hold.

In an influential paper in econometrics, Heckman (1978) used a latent Index/simultaneous equations model with normally distributed errors to develop estimation strategles for treatment effects in nonlinear limited dependent variable models. A commonly encountered model of this type is bivarlate probit (e.g., Ashford and Snowden 1970, Amemiya 1978) which, like most latent variable models, does not satisfy the 1dentification conditions required for linear IV techniques to consistently estimate average treatment effects. Section 5 of the paper contains a detalled study of average treatment effects in bivariate probit. Included in this section are the results of a Monte Carlo sampling experiment that compares the finite sample performance of Maximum Likelihood (ML) and IV estimates of average treatment effects in correctly specified and misspecifled models. The paper concludes in Section 6 .

1. The Effect of Vietnam Veteran Status on Mortality

In addition to combat-related injuries, mflitary service during the Vietnam war may also affect civilian mortality because of wartime access to narcotics, exposure to toxins like Agent Orange, and causes related to Post-Traumatic Stress Syndrome such as sulcide. Hearst, Newman and Hulley (1986) showed that men with sequence numbers that put them at high risk of being drafted in the Vietnam Era draft lotteries had elevated mortality risk after their discharge from the military. They attribute this elevated 
risk to a higher probability of military service because between 1970 and 1973, the risk of beling drafted was randomly assigned in a series of lotterles baged on dates of birth. Each date of birth in the cohorts at risk of being drafted was assigned a Random Sequence Number (RSN) from 1 . 365. The Selective Service called men for Induction by RSN up to a celing determined by the Department of Defense. Men born in 1950 were called up to RSN 195, men born In RSN 1951 were called up to RSN 125, and men born in 1952 were called up to RSN 95.

In their paper, Hearst, Newman and Hulley focus on comparisons of mortality risk by draft-eligibility status. For example, they compare the number of deaths of men born in 1950 with RSN below 195 to the number of deaths of men born in 1950 with RSN above 195. This procedure can be used to provide a valid estimate of the effects of military service on mortality if draft-eligibility is correlated with civilian mortality solely by virtue of its correlation with veteran status. Although not explicitly stated, the assumptions and estimation techniques used by Hearst, Newman, and Hulley can be Interpreted as an application of IV estimation to the IInear model

$$
y_{1}-\alpha_{c}+\beta s_{1}+x_{1} \gamma
$$

where $y_{1}$ is a binary Indicator of death in the study interval, $s_{1}$ Indicates veteran status, $\beta$ is the treatment effect of interest, $\alpha_{c}$ is a cohortspecific intercept, and $x_{1}$ is an unobserved confounding variable. 1

The key Identifying assumption Justifying IV estimation in this case Is that $E\left[x_{i} \mid\right.$ draft-eligibility status $]-0$. Given this assumption, a consistent estimate of $\beta$ can be obtained by applying the simplest IV

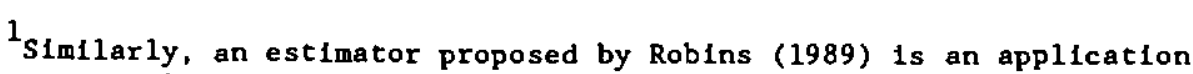
of instrumental variables techniques to a linear model for survival analysis. 
estimator - Wald'a (1940) method of fitting atralght 11 nes - to data for a single cohort and race. ${ }^{2}$ To see this, note that because drafteliglbility is uncorrelated with $x_{1}$, a consistent Wald estimete can be computed by dividing the data by draft-eligibility status:

$$
\beta=\left(\overline{\mathbf{y}}^{\mathbf{e}}-\overline{\mathbf{y}}^{\mathbf{n}}\right) /\left(\hat{\mathbf{p}}^{\mathbf{e}}-\hat{\mathbf{p}}^{\mathbf{n}}\right)
$$

where $\dot{y}$ is the probability of death, $\hat{p}$ is the probability of veteran status, and superscript $e$ and superscript $n$ denote the draft-eligible and draft-ineligible samples. The instrument here is an indicator of draft-eligibility status. Using data in the Appendix Table for white men born in 1950, we have

$$
\beta-(.0204-.0195) /(.3527-.1933)-.00564,
$$

so that beling a veteran raises mortality risk for this group by half a percentage point - a 258 increase in risk. ${ }^{3}$

An efficient linear combination of alternative wald estimates of the same parameter can be computed by Generalized Least Squares (GLS) estimation of the equation

2The observation that Wald's estimator is also an instrumental variables estimator is usually attributed to Durbin (1954). The results in Hearst, Newman and Hulley (1986) are actually for relative risk, in contrast to estimates of the "risk-difference" generated by Wald's method. It can be shown, however, that the Hearst, Newman, and Hulley relative risk estimates are a simple transformation of Wald risk-difference estimates.

${ }^{3}$ A standard error for the Wald estimate is calculated easily under the null hypothesis that $\beta-0$. All moments in this example are independent, so the limiting distribution of $\left(\bar{y}^{\mathrm{e}}-\hat{y}^{\mathrm{n}}\right) /\left(\hat{\mathrm{p}}^{\mathrm{e}} \cdot \hat{\mathrm{p}}^{\mathrm{n}}\right)$, is $1 /\left(p\right.$. $\left.p^{n}\right)$ times the limiting distribution of the numerator. The denominators in $\bar{y}$ and $y^{n}$ are $\mathrm{N}^{\mathrm{e}}-127,500$ and $\mathrm{N}^{\mathrm{n}}-111,200$. The sampling variance of the Wald estimate is therefore

$$
\left[1 /\left(\hat{p}^{e}-\hat{p}^{n}\right)\right]^{2}\left[\left[\dot{y}^{e}\left(1-\bar{y}^{e}\right)\right] / N^{e}+\left[\bar{y}^{n}\left(1-\dot{y}^{n}\right)\right] / N^{n}\right]
$$

The estimated standard error is 0.00368 . 


$$
\bar{y}_{c r j}-\alpha_{c}+\beta_{0} R_{c r j}+\hat{p}_{c r j} \beta_{1}+\dot{\varepsilon}_{c r j}
$$

where the subscripts $c, r$ and $f$ index birth cohort, race and $d r a f t$ -

eliglbility status, and the data are grouped into averages for cells deflned by these three varlables. Since there are 3 birth cohorts, 2 races, and 2 eligibility groups, equation (1.3) is fit to 12 observations. Angrist (1991) shows that GLS estimates of grouped equations such as (1.3) are the same as Two-Stage Least Squares (TSLS) estimates that efficiently combine all possible IV estimates. In this case, the TSLS instrument set contains dumny varlables for the full set of cohort, race and draft. eligibility interactions. Because the estimating equation includes main effects for cohort and race, the effect of veteran status is identifled by the exclusion of draft-eligibility status for each race and cohort from the estimating equation.

Figure 1 presents a graphical version of equation (1.3) for sulcide, the major cause of death associated with veteran status in these data. The figure graphs residuals from a regression of sulcide probabilities on race and cohort dumbles, against the corresponding residuals for veteran status probabilities. Thus, the slope of the line in the figure is an estimate of $\beta_{1} \ldots$ in this case, equal to 0.258 percentage points, with a standard error of 0.06 .

Although Figure 1 clearly shows a strong linear relationship, for a variety of reasons most textbook discussions of limited dependent variable models (e.g., Maddala 1983) argue that the linear model used in this lllustration is inappropriate for binary outcomes. Problems include the fact that fitted values in the linear model are not bounded between zero and one. Also, least squares eștimation of a linear model does not reflect the fact that a probability distribution is being parameterized, as would, 
say, ML estimation of a logit model. Note, however, that IInear IV estimation breaks down in logistic or other nonlinear regression models because the IV moment condition fails to hold: the conditional expectation of nonlinear transformations of $\alpha_{c}+\beta s_{1}+x_{1} \gamma$ is not equal to the conditional expectation of the outcome varlable, even when conditional varlables are mean-1ndependent of unobservables. Such problems notwithstanding. part of the purpose of this paper 18 to offer formal arguments that help rationalize linear IV estimation in nonlinear models.

\section{Nonlinear Yodels vith Omitted Covarlates}

The general model of Interest relates $n$ observations on an outcome varlable, $y_{1}$, to a treatment indicator, $s_{1}$, in the following manner:

$$
\begin{aligned}
& E\left[y_{1} \mid s_{1}, u_{1}, z_{1}\right]-E\left[s_{1}, u_{1} ; \beta\right] \\
& E\left[s_{1} \mid u_{1}, z_{1}\right]-G\left[z_{1}, u_{1} ; \gamma\right],
\end{aligned}
$$

where $v_{1}$ is an $r \times 1$ vector of covarlates unobserved by the econometriclan, $Z_{1}$ is a $q \times 1$ vector of potential instrumental varlables, $F$ and $G$ are functions, and $\beta$ and $\gamma$ are parameter vectors. Observed covarlates are held constant by estimating in subpopulations (1.e., racial groups). A nonlinear example of (1.1) Is given In Rosenbaum and Rubin's (1983) study of the effect of an unobserved binary covarlate on estimated average treatment effects in a model for binary outcomes .

The $n$ observations are assumed to be Independent and Identically distributed. The development that follows can be applied to heterogeneously distributed samples with few modifications. The vector $z_{I}$ Includes a constant and satisfles rank and independence conditions: 
Assumption 1: (1) $\mathrm{E}\left[Z_{1}^{\prime}\left(s_{1} 1\right)\right]-\Phi_{z s}$, where the rank of $\Phi_{z s} \geq 2$, (11) $v_{1}$ and $z_{i}$ are independent.

Assumption $1(1)$ is the standard requirement that potential instruments be correlated with regressors. The $z_{1}$ are potential instruments because equation (2.1) implies

$$
E\left(y_{1}-F\left[s_{1}, u_{1} ; g\right] \mid z_{1}\right)=0
$$

by the law of iterated expectations, and because $z_{1}$ is independent of unobservables by $A 2(11)$.

In many econometric applications, attention is focused on identification strategles for theoretical parameters in the outcome equation ( $\beta^{\prime} s$ ) such as marginal rates of substitution. But in evaluation studies, the substantive question motivating applied research concerns the effect of treatment on an outcome, as opposed to the magnitude of structural parameters that arise in economic theory. I therefore focus on the identification of average treatment effects. For model (2.1) the average treatment effect is defined as follows:

$$
\pi_{1}=E\left\{F\left[1, U_{1} ; \beta\right]-F\left[0, v_{1} ; \beta\right]\right\}
$$

The average treatment effect in this model is primarily of interest because of its relationship to the Holland-Rubin (Holland 1986, Rubin 1974) definition of an average causal effect. The Holland-Rubin definition of causality is based on the notion that for each Individual we can concelve of outcomes that would occur with and without treatment. The average causal effect is the expectation of an outcome variable when all 
Individuals in a given population receive treatment minus the expectation of an outcome varlable when no individuals recelve treatment. The fundamental problem of causal inference is that in practice, we neyer observe outcomes for any single individual both with and without treatment (Holland 1986). Nevertheless, we can sometimes estimate average causal effects. The parameter $\pi_{1}$ is an average causal effect as long as the average of $y_{1}$ given $a_{1}$ and $v_{1}$ is an unblased estimate of the average of $y_{1}$ if all members of the population with a given value of $v_{1}$ had the same value of $s_{1}$. Rosenbaum and Rubin (1983) call this property strong ignorability of $\underline{s}_{1}$ given $\underline{U}_{1}$. For exemple, $s_{1}$ is strongly ignorable given $U_{1}$ if 1 t is randomly assigned conditional on $v_{1}$.

*

\subsection{Identification conditions}

The Identification conditions for IV estimation of $\pi_{1}$ involve the additive separability of $F$ and $G$, defined as follows:

Assumption 2: (1) $F\left[s_{1}, v_{1} ; \beta\right]-f_{1}\left(s_{1} ; \beta\right)+f_{2}\left(v_{1} ; \beta\right)$, (11) $G\left[Z_{1}, U_{1} ; \gamma\right]-g_{1}\left(Z_{1} ; \gamma\right)+g_{2}\left(U_{1} ; \gamma\right)$.

where $f_{1}, f_{2}, g_{1}$, and $g_{2}$ are functions. ${ }^{4}$ Assumption 2 characterizes the class of models for which average treatment effects can be estimated using inear IV techniques. This result is formalized in the following proposition:

Proposition 1: Let $\pi_{1}$ be the average treatment effect defined in $(2.4)$.

\footnotetext{
${ }^{4}$ Because $s_{1}$ is binary, we could replace $f_{1}\left(s_{1} ; \beta\right)$ with $f_{10}+f_{11} s_{1}$,
where $f_{10}$ and $f_{11}$ are constants.
} 
Then for some constant $\pi_{0}$ and for all $y_{1}, U_{1}$ and $z_{1}$ satisfying (2.1). (2.2), and Assumption 1(11):

$$
E\left[y_{1} \mid z_{1}\right]-\pi_{0}+\pi_{1} E\left[s_{1} \mid z_{1}\right]
$$

if and only if either or both Assumption 2(1) and Assumption 2(11) holds.

Proof. Sufficiency of $2(1)$ is immediate because of the independence of $U_{1}$ and $z_{1}$. To establish sufficiency of $2(11)$, write (1.3) as

$$
\left.E\left[y_{1} \mid z_{1}\right]-E\left|F\left[s_{1}, U_{1} ; \beta\right]\right| z_{1}\right)-\kappa_{0}+E\left[\pi_{1} s_{1} \mid z_{1}\right]
$$

where

$$
\kappa_{0}=E\left(F\left[0, U_{1} ; \beta\right] \mid z_{1}, \quad \pi_{1}-F\left[1, U_{1} ; \beta\right]-F\left[0, U_{1} ; \beta\right] .\right.
$$

Note that

$$
\begin{aligned}
E\left[\pi_{1} s_{1} \mid z_{1}\right] & -E\left(\pi_{1} E\left[s_{1} \mid z_{1}, U_{1}\right] \mid z_{1}\right) \\
& -E\left(\pi_{1}\left[g_{1}\left(z_{1} ; \gamma\right)+g_{2}\left(U_{1} ; \gamma\right)\right] \mid z_{1}\right] \\
& -g_{1}\left(z_{1} ; \gamma\right) E\left[\pi_{1} \mid z_{1}\right]+E\left[\pi_{1} g_{2}\left(U_{1} ; \gamma\right) \mid z_{1}\right] .
\end{aligned}
$$

But independence of $U_{1}$ and $z_{1}$ fmplies that $E\left[\pi_{1} g_{2}\left(U_{1} ; \gamma\right) \mid z_{1}\right]$ is a constant, say, $\kappa_{1}$. Also, $E\left[\pi_{1} \mid z_{1}\right]-\pi_{1}$, the average treatment effect, and

$$
g_{1}\left(z_{1} ; \gamma\right)-E\left[s_{1} \mid z_{1}\right]-E\left[g_{2}\left(U_{1} ; \gamma\right) \mid z_{1}\right]-E\left[s_{1} \mid z_{1}\right]-\kappa_{2} .
$$

Therefore,

$$
E\left[\pi_{1} s_{1} \mid z_{1}\right]-\left(E\left[s_{1} \mid z_{1}\right]-\kappa_{2}\right) \pi_{1}+\kappa_{1}
$$

so that sufficlency holds for $\pi_{0}=\kappa_{0}+\kappa_{1}-\kappa_{2} \pi_{1}$.

Necessity is established by showing that the proposition cannot hold for some $z_{1}$ satisfying (2.1), (2.2) and Condition 1 when neither $2(1)$ or 2(11) hold. Suppose that $2(1)$ does not hold, that $z_{1}-\left[\begin{array}{ll}1 & z_{1}\end{array}\right]^{\prime}$, where $z_{1}$ is a single dummy variable, and that 2 (11) does not hold because

$$
G\left[Z_{i}, U_{1} ; \gamma\right]-g_{1}\left(Z_{1} ; \gamma\right)+g_{2}\left(U_{1} ; \gamma\right)+z_{1} g_{3}\left(U_{1} ; \gamma\right),
$$

where $g_{3}$ is a function of $U_{1}$. Then, 


$$
E\left[y_{1} \mid z_{1}\right]-\pi_{0}+\pi_{1} E\left[s_{1} \mid z_{1}\right]+z_{1} E\left[\pi_{1} g_{3}\left(u_{1} ; \gamma\right)\right],
$$

and $E\left[\pi_{1} g_{3}\left(U_{1} ; \gamma\right)\right] 1 s$ a constant that is not generally equal to zero. This completes the proof.

In practice, the plausibility of either Assumption 2(1) or Assumption 2(11) has to be considered on a case by case basis. For example, latent Index models other than the uniform-11near probability model are unlikely to be additively separable. On the other hand, over a limited range that is generally around the median, many cumulative distribution functions are approximately linear. If the variation in the outcome equation or in the expectation of the endogenous regressor is close to this range, linear IV estimation may give a good approximation to the true average treatment effect in models with dumay endogenous variables.

The usefulness of Proposition 1 for econometricians should also be evaluated in 11ght of the fact that economic theory usually provides little guidance as to appropriate parametric distributional assumptions. In some circumstances, restrictions on functional form might be easier to rationalize and test than a distributional assumption. For example, standard instrument-error orthogonality test statistics (e.g. . Newey 1985b) may have the power to detect fallure of the functional form assumptions required to Identify average treatment effects. Moreover, if the underlying distributions or functional forms are misspecified, it becomes an empirical question whether linear IV estimators do a worse job than ML estimators. This is among the questions investigated in Section 5.

It should also be noted that many of the existing non-parametric procedures developed by econometriclans for the estimation of latent variable models cannot be used to estimate average treatment effects. For 
example. Stoker's (1986) average derlvative estlmator cannot be used to estimate the effect of discrete explanatory vartables. Newey's (1985a) application of Manski's (1975) maximum score estimator to binary response models with endogenous regressors consistently estimates the coefficients on discrete endogenous regressors up to scale. Simflarly, Newey's (1986) non-parametric estimator for limited dependent varlable models with endogenous regressors conststently estlmates ratios of index coefficlents. But netther of the Newey procedures recovers enough Information to estimate the average effect of treatment on outcomes. Heckman's (1990) results on the nonparametric Identiflability of treatment effects may also be of limited practical use because these results require continuously distributed regressors.

\subsection{The Large Sample Blas of IV Estimates}

Equation (3.1) can be used to make some general statements about the asymptotic blas of IV estimates of the average treatment effect in models where netther $F$ or $G$ are additively separable. Here it is useful to note that, as a consequence of (3.1), the model can be written ustng a random coefficients notation: 5

$$
y_{1}-\pi_{1}+\pi_{1} s_{1}+c_{1}
$$

where $\kappa_{1}-F\left[0, v_{1} ; \theta\right]$ and $E\left[c_{1} \mid z_{1}\right]-0$. Therefore,

${ }^{5}$ Heckman and Robb (1985) also discuss instrumental variables estimation of a random treatment effect. In their discusston of random coefficlents models for treatment effects, Heckman and Robb suggest that consistent estimates be obtalned through by applying a combination of behavioral (latent Index) and distributional assumptions that can be used to compute the theoretical conditional expectation of treatment given instruments and covariates. 


$$
y_{1}-\kappa_{0}+\pi_{1} s_{1}+\left[c_{1}+\left(\kappa_{1}-\kappa_{0}\right)+s_{1}\left(\pi_{1}-\pi_{1}\right)\right]
$$

Since $c_{1}$ and $\left(\kappa_{1}-\kappa_{0}\right)$ are uncorrelated with $z_{1}$. TSLS estimates of $\pi_{1}$ converge to

$$
\pi_{1}+\underset{n \rightarrow \infty}{\operatorname{plim}}\left[\left(\Sigma \hat{s}_{1}^{2}\right)^{-1} \Sigma \hat{s}_{1} s_{1}\left(\pi_{1}-\pi_{1}\right)\right]
$$

where $\hat{s}_{1}-z_{1}\left(z^{\prime} z\right)^{-1} z^{\prime} s-\dot{s}_{\text {, and }} \dot{s}$ is the sample mean of $s_{1}$.

The TSLS estimate of $\pi_{1}$ is consistent under A2(1) because $\pi_{1}$ is identically equal to $\pi_{1}$. The TSLS estimate of $\pi_{1}$ is consistent under A2(11) because $\underset{n \rightarrow \infty}{p 11 m} \sum \hat{s}_{1} s_{1}\left(\pi_{1}-\pi_{1}\right)$ ] is zero in this case, even though $\pi_{1}$ is not equal to $\pi_{1}$ for all 1 . To see this, let $\delta$ be the vector of population regression coefficients for a regression of $s_{1}$ on $z_{1}$, and let $\bar{z}_{i}$ equal $z_{i}$ minus its mean. We have

$$
\underset{n \rightarrow \infty}{p l i m} \sum\left[s_{1}\left(\pi_{1}-\pi_{1}\right) \hat{s}_{1}\right] / n-E\left[E\left[s_{1}\left(\pi_{1}-\pi_{1}\right) \mid z_{1}\right] \bar{z}_{1}\right) \delta .
$$

by the weak law of large numbers. But $E\left[s_{1}\left(\pi_{1}-\pi_{1}\right) \mid z_{1}\right]$ is constant under $A 2(11)$ and $E\left(\tilde{z}_{1}\right)-0$.

To evaluate expression (4.3) for the general case, note that

and

$$
\underset{n \rightarrow \infty}{p l i m} \sum \hat{s}_{i}^{2} / n-\delta^{\prime} E\left(\bar{z}_{i}^{\prime} \bar{z}_{i}\right) \delta
$$

$$
\underset{n \rightarrow \infty}{p \lim } \sum\left[s_{1}\left(\pi_{1}-\pi_{1}\right) \hat{s}_{1}\right] / n-E\left[G\left(z_{1}, v_{i} ; \gamma\right)\left(\pi_{1}-\pi_{1}\right) \bar{z}_{1}\right] \delta
$$

The asymptotic bias of a linear IV estimate of the average treatment effect 1s therefore

$$
\left[\delta^{\prime} E\left(\bar{z}_{1} \cdot \bar{z}_{1}\right) \delta\right]^{-1} E\left[G\left(z_{1}, u_{1} ; \gamma\right)\left(\pi_{1}-\pi_{1}\right) \bar{z}_{1}\right] \delta .
$$


The bias formula can be simplified further if $G\left(z_{1}, U_{1}: \gamma\right)$ is linear and $\bar{z}_{i}$ is a scalar:

$$
G\left(z_{1}, U_{i} ; \gamma\right)-\gamma_{0}+\gamma_{1} \bar{z}_{1}+\gamma_{2} \bar{u}_{1}+\gamma_{3} \bar{u}_{1} \bar{z}_{1},
$$

where $\bar{u}_{1}$ 1s $U_{1}$ minus 1 tes mean. Expression (3.4) can now be written,

$$
\left[\gamma_{3} / \gamma_{1}\right] \mathrm{E}\left[\vec{u}_{1}\left(\pi_{1}-\pi_{1}\right)\right]
$$

because $\delta-\gamma_{1}$ in this case. This version of the bias formula is useful because it highlights the role of both the interaction between $U_{1}$ and $Z_{i}$ in G, and the covarlance of the treatment effect with unobserved characteristics, in determining the asymptotic blas of IV estimates. The Interaction term $\gamma_{3}$ is a measure of the non-separability of $G$, while $E\left[\bar{u}_{i}\left(\pi_{i}-\pi_{1}\right)\right]$ is a measure of the non-separabllity of $F$. The bias asymptotic is also inversely proportional to a measure of the quality of the instruments, $\gamma_{1}$.

\subsection{Optimal Weighting and Cholce of Instruments \\ Properties of the conditional varlance of residuals determine the appropriate Generalized Least Squares (GLS) welghting matrix for IV estimators. Write}

$$
\nu_{1}-\left[\varepsilon_{i}+\left(\kappa_{1}-\pi_{0}\right)+s_{i}\left(\pi_{i}-\pi_{1}\right)\right]
$$

for the compound error term in equation (4.2). If the outcome varlable is continuous and estimation is based on Assumption 2(1) so that $\nu_{1}-\varepsilon_{1}$. then 1 may be reasonable to assume that $\nu_{1}$ is homoscedastic. In this case, conventional TSLS is the most efficlent way to use the elements of $z_{i}$ 
as instruments, and TSLS covarlance formulas w111 give asymptotically

correct standard errors for estimates of average treatment effects. But if estimation Is Justified by A2(11), the presence of the terms $\left(x_{1}-x_{0}\right)$ and $\left(\pi_{1}-\pi_{1}\right) s_{1}$ in $\nu_{1}$ suggests that $\nu_{1}$ will be heteroscedastic even If $c_{1}$ Is homoscedastic.

Chamberlain's (1987) resulta on efficient estimation under conditional moment restrictions Imply that the optimal instruments are a function of both $Z_{1}$ and the conditional variance of residuals given $Z_{1}$. For estimation of the coefficient on a dummy variable with Independent observations, the optimal Instruments are (Newey 1989):

$$
D\left[z_{1}\right]-\phi\left(Z_{1}\right)^{-1} *\left[1 E\left(s_{1} \mid z_{1}\right)\right]^{\prime}
$$

where $\psi\left(Z_{1}\right)=E\left[\nu_{1}^{2} \mid Z_{1}\right]$. Estimates computed using $D\left[Z_{1}\right]$ as Instruments asymptotically attain the variance bound for conditional moments estimation. As a practical matter, however, it often Infeasible to use the optimal instruments because both $E\left[s_{1} \mid Z_{1}\right]$ and $\phi\left(Z_{i}\right)$ are unknown. An Important exception to this is when $Z_{1}$ is discrete with finite support. With discrete $Z_{1}$, the optimal IV estimator is a feasible weighted least squares estimator. This estimator can be computed by using a full set of dummy variables to Indicate each value of $Z_{1}$ as Instruments in White (1982) TSLS estimation. 6

${ }^{6}$ Suppose that $Z_{j}$ can take on $J-1, \ldots, \ldots$ values and let $R$ denote a matrix of $J^{i}$ dummy varlables that indicate each value of $Z$. That Is, $R_{i j}-1\left(Z_{i}-J\right)$. Using $R$ as the matrix of instruments, White's TSLS estimator can be interpreted as instrumental variables estimation with instruments equal to $R\left[\Sigma R_{1} R_{1}^{\prime} \hat{v}_{1}^{2} / n\right]^{-1}\left[R^{\prime} X / n\right]$, where $X-[\iota s]$. ThIs simplifies to $R *\left[\bar{x}_{j} / \hat{o}_{j}^{2}\right]$ where $\left[\bar{x}_{j} / \hat{o}_{j}^{2}\right]$ is a matrix with $J$ rows each 


\subsection{Average Treatment Effects in Bivarlate Probit}

An important special case of the problem considered in this paper is the estimation of treatment effects in models with qualitative or binary dependent variables. Qualitative response models with endogenous regressors have generated a large theoretical and applied literature. Ashford and Snowden (1970) are usually credited with introducing a bivariate probit model in blometrics and Amemiya (1974) developed a minimum chi-square estimator for this model. Bivariate probit is also among the latent index/simultaneous equations models outlined by Heckman (1978). A variety of econometric aspects of the model are considered by Amemiya (1978) and Newey (1987), and some applications are described in Maddala (1983). The latent index approach to qualitative response analysis is popular in econometrics because the indices correspond to unobserved utilities in the theory of discrete cholce.

Blvariate probit with endogenous dummy regressors can be motivated by the following latent index model:

$$
\begin{aligned}
y_{1}-1 & \text { if } & y_{1}^{*}-\beta_{0}+\beta_{1} s_{1}-\left[\eta_{11}-u_{1} \lambda\right]>0 \\
-0 & & \text { otherwise }
\end{aligned}
$$

$$
\begin{aligned}
& s_{1}-1 \text { if } s_{i}^{*}-\gamma_{0}+\gamma_{1} z_{1}-\left[\eta_{21}-u_{1}\right]>0 \\
& \text { - } 0 \text { otherwise, }
\end{aligned}
$$

where $\eta_{1 i}, \eta_{21}$, and $u_{i}$ are independent, normally distributed random

containing the average of $X$ given $z-j$, divided by the variance of $X$ given $2-j$. For continuous $z_{1}$ in a homoscedastic model, Newey (1989) proposes a number of asymptotic approximations to the optimal instruments. 
varlables. The treatment Indicator, $s_{1}$, is endogenous because the compound error terms,

$$
\eta_{11}^{*}=\eta_{11}-u_{1} \lambda \text { and } \eta_{21}^{*}=\eta_{21}=u_{1}
$$

are correlated. Note that this formulation preserves the definition of endogenelty Impliclt in the previous sections: if all relevant covariates were observed, then the effect of treatment on $y_{1}$ could be estimated using single equation techniques.

The compound error terms in (5.1) and (5.2) are also normally distributed, with covarlance matrix:

$$
\left[\begin{array}{ll}
\sigma_{1}^{2}+\sigma_{u}^{2} \lambda^{2} & \sigma_{u}^{2} \lambda \\
\sigma_{u}^{2} \lambda & \sigma_{2}^{2}+\sigma_{u}^{2}
\end{array}\right],
$$

where $\sigma_{1}^{2}, \sigma_{2}^{2}$, and $\sigma_{u}^{2}$ are the varlances of $\eta_{1 i}, \eta_{2 i}$, and $u_{1}$. If $\sigma_{1}^{2}=$ $\sigma_{2}^{2}-\sigma_{u}^{2}$, then the correlation between $\eta_{11}^{*}$ and $\eta_{21}^{*}$ is parameterized by $\lambda$

as

$$
\rho-(1 / \sqrt{2}) *\left[\lambda / \sqrt{ }\left(1+\lambda^{2}\right)\right]
$$

The average effect of treatment on $y_{1}$ in (5.1) is

$$
E\left(\Phi\left[\left(\beta_{0}+\beta_{1}+u_{i} \lambda\right) / \sigma_{1}\right] \cdot \Phi\left[\left(\beta_{0}+u_{i} \lambda\right) / \sigma_{1}\right]\right)
$$

where $\Phi[\cdot]$ is the standard normal cumulative distribution function. This expression simplifies further because the assumption of bivariate normallty leads to a closed form for the expectation. Using the convolution properties of the normal distribution (see, e.g., McFadden and Reld (1975]), expression (5.4) can be written 


$$
\pi_{1}^{\star}=\Phi\left[\left(\beta_{0}+\beta_{1}\right) / \sqrt{ }\left(\sigma_{1}^{2}+\sigma_{u}^{2} \lambda^{2}\right)\right]-\Phi\left[\beta_{0} / \sqrt{ }\left(\sigma_{1}^{2}+\sigma_{u}^{2} \lambda^{2}\right)\right]
$$

Note that ML estimation Identifies the standardized coefficients, $\beta_{0} / J\left(\sigma_{1}^{2}\right.$ $\left.+\sigma_{u}^{2} \lambda^{2}\right)$ and $\beta_{1} / J\left(\sigma_{1}^{2}+\sigma_{u}^{2} \lambda^{2}\right)$. Therefore, ML estimates of $\pi_{1}^{*}$ can be computed by evaluating (5.5) at the coefficient estimates.

\subsection{Finite Sample Behavior}

This section compares ML and IV estimates of $\pi_{1}^{*}$ in a small sampling experiment designed to mimic situations encountered in econometric applications. In each experimental design, the true treatment effect is set at 10 percent, which is in the range of the estimated effects of manpower training on employment rates in four social experiments (ham and LaLonde 1990). The instruments are drawn from a discrete uniform distribution with 8 points of support in increments of 1 . Angrist (1990) uses a discrete uniformly distributed instrument to estimated the effects of military service, and Angrist and Krueger (1991) use a discrete uniformly distributed instrument to estimate the monetary returns to education. The number of replications for each experiment is 500, and results are presented for samples of 400 and 800 observations. 7 These sample sizes are in a range commonly encountered in econometric evaluation research (e.g., LaLonde 1986). The resulting blas calculations should provide an upper bound for applications like the mortality example in Section 1, where the treatment effects are so small that the outcome equations are approximately linear.

The base design sets $\beta_{0}$ equal to zero, and $\beta_{1}$ to $\Phi^{-1}(.6) \approx 0.25$,

7 The computations were made using LIMDEP on microcomputers. Maximum Likelihood estimates were computed using the DFP algorithm from starting values of zero in each replication. 
so that the treatment effect consists of a movement from 0.5 to 0.6 . In equation (4.2), $\gamma_{0}$ is set to zero, $\gamma_{1}$ to 0.25 , and the instrument ranges from -3.5 to 3.5 . The resulting first-stage equation generates variation In $E\left[s_{1} \mid z_{1}\right]$ from $\Phi(.875)-.81$ to $\Phi(-.875)-.19$. The errors are all normally distributed. The variances $\sigma_{1}^{2}, \sigma_{2}^{2}$, and $\sigma_{\mathrm{u}}^{2}$ equal $1 / 2$, and $\lambda$ is equal to 1 , so that the compound error terms have unit variance and a correlation coefficient of $1 / 2$. This base design represents a promising scenario for IV estimation: variation In both $F$ and $G$ is close to the median, so that $F$ and $G$ should approximately satisfy Assumptions $2(1)$ and 2(11). Moreover, the Instrument is highly correlated with the endogenous regressor, tracing out 60 percent of the distribution of $\eta_{21}^{\star}$.

Table 1 presents experimental results for the base design. Columns 1 . 7 report the mean, standard deviation (SD), root mean squared error (RMSE), mean absolute error (MAE), lower quartile (LQ), median (MD), and upper quart1le (UQ) of the estimates from 500 replications. Rows of the table report statistics for maximum likelihood estimates (MLE), just-identifled IV estimates using only $z_{1}$ and a constant as Instruments, TSLS estimates using 8 dummies to Indicate each value of $z_{i}$ as Instrumerts (Dumny IV), TSLS estimates using 8 dummies in White's (1982) efficient estimator (Efficlent IV), and Ordinary least Squares (OLS) estimates of a linear probability model. The MLE's are consistent and efficlent for the bivarlate probit model. The IV estimator is consistent under Assumptions A2(1) or A2(11); Dummy IV is consistent and asymptotically efficient under A2(1) if $\nu_{1}$ is homoscedastic; Efficient IV is consistent and asymptotically efficlent under A2(1) or A2(11). ${ }^{8}$ The oLs estimates are

${ }^{8}$ Only one set of just-1dentifled IV estimates are presented because instrumental variables estimates in just-identifled modeis are unaffected by the cholce of weighting matrix. 
Identical to estimates of the average treatment effect that would arise from single equation problt estimation using $s_{1}$ as a regressor.

The means of the IV and ML estimates are within sampling variance of each other in both the 400 and 800 observation samples. The Dummy IV and Efflclent IV estlmates are blased towards the OLS estimate, which Is nearly 4 times larger than the true treatment effect. 9 The blas of the Dumy and Efficlent IV estimates is considerably worse in the smaller sample. The contrast between the just-Identified IV estimates and the Dummy or Efflclent IV estimates Illustrates the trade-off between Increasing bias and Increasing efficlency as the number of Instruments increase. In both samples, the MLE's have the lowest RMSE. Other than the oLs estimates, the MLE's are also most efflclent, although the varlous IV estimators have only modestly larger sampling varlance. The Efflclent IV estimates are always slightly more varlable than the asymptotically less efficient Dummy IV estimates. The quartiles do not Indicate a significantly larger number of extreme values for the IV estimates than for the MLE's.

The discussion in Section 4.1 suggests that IV estimators should perform more poorly when the treatment effect shifts the distribution of the latent Index at a point farther from the median, and when the Instruments shift the distribution of the first-stage latent Index at a point farther from the median. Table 2 reports results from a design the same as the base design, except that the treatment effect consists of a movement from 0.85 to 0.95 . Th1s constitutes a larger deviation from A2(1) than In the base design, although A2(11) is st111 approximately satisfled. All the estimates in Table 2 tend to be somewhat lower than the

${ }^{9}$ In a bivarlate example, Nelson and Startz (1990) stiow analytically that the finite-sample central tendency of consistent instrumental varlables estimates is blased towards the probability 11mit of ols estimates. 
true effect, whereas in the base design they are higher. As expected, the IV estimates are farther from the true effect than the MLE's, but the Dummy and Efficient IV estimates are closer. This may be because a positive small sample blas in these estimates offsets negative asymptotic blas.

Table 3 reports results from a design the same as the base design, except that the eight values taken by the instrument shift $E\left[s_{1} \mid z_{1}\right]$ in the lower tail of the latent index distribution, from 0.05 to 0.35 .10 This constitutes a stronger violation of A2(11), leaving A2(1) approximately satisfled. All the estimates are now more varlable, and the Dumny and Efficlent IV estimates are substantially upwards blased in the 400 observation sample. But in the larger sample, in spite of a larger bias, the Dumny and Efficient IV estimates have lower RMSE than the ML estimate. Overall, the evidence from Tables 1,2 and 3 suggests that IV estimators do not perform appreciably worse than the correctly specified ML estimator, especlally in large samples.

Table 4 reports results from a design that combines the upper tall treatment effect of Table 2 with the lower tall first stage of Table 3 . The combined violation of assumptions $2(1)$ and $2(1 i)$ leads to a considerable deterioration in the finite sample performance of all the IV estimators. In fact, OLS now has lower RMSE than any of the IV estimates. However, the MLE performs equally badly, with a mean that tends to be half the size of the true treatment effect. Moreover, roughly half of the MLE replications falled to converge from starting values of zero. MLE's for the convergent subsample (In parentheses) also have a larger MAE than the IV estinates.

Tables 5 and 6 report the results of sampling experiments in which

${ }^{10}$ The instruments range from -3.5 to $3.5, \gamma_{0}--1.02$, and $\gamma_{1}=0.181$ 
bivarlate probit and IV techniques are used to estimate average treatment effects in models where the underlying error distributions are non-normal. Table 5 presents results from the base design where the underlying error distributions are $x^{2}(1)$ instead of $N(0, J .5)$. The compound error in this case is distributed as $x^{2}(2)$, because it is the sum of two $x^{2}(1)$ random variables. Table 6 presents results from a modified base design where the treatment effect consists of a movement from 0.4 to 0.5 , and the underlying error distributions are uniform on $[0,1]$, so that the compound error terms are triangular on $[0,2]$ with a mode of one. ${ }^{11}$ The design used to produce Table 6 comes close to satisfying both $A 2(1)$ and $A 2(11)$. The additive separability assumptions are not satisfied exactly in spite of the uniform distribution of $\eta_{11}$ and $\eta_{21}$ because the indices, $\beta_{0}+\beta_{1} \cdot u_{1} \lambda$ and $\gamma_{1}+$ $\gamma_{1} z_{1}-u_{1}$, are not guaranteed to be between $z$ ero and one.

Results from the models with chi-square error distributions show the IV and MLE estimators with almost identical means. The MLE still has lower sampling varlance, however, and lower mean squared error. Results from the models with uniform error distributions show the IV estimator closer to the true effect of 10 percent than the MLE. In the uniform designs, the median of the IV sampling distribution is also closer to the true effect than the median of the MLE sampling distribution. Again, however, larger sampling varfance raises the mean squared error of the IV estimator above that of the MLE.

In both Tables 5 and 6 , there is upward bias in the Dummy and Efficient IV estimates, although the bias of the Dummy and IV estimates

11 As in Table 5, for the design reported in Table 6 the compound error terms are the sum of $u_{\text {, }}$ and the $\eta_{1}$ 's. For Table 5 , design parameters are: $\beta_{0}-1.3871, \beta_{1}-1.8331, \gamma_{0}-0, \gamma_{1}-3 / 8$; for Table 6 design parameters are: $\beta_{0}=\sqrt{.8}, \beta_{1}=1 \cdot j .8, \gamma_{0}-0.5, \gamma_{1}-0.1$. 
falls with increasing sample size, while the blas of the MLE does not. In smaller samples, the simple IV estimator has lower blas than the MLE but is less efficient. The contrast between the results in Table 4 and the results in Tables 5 and 6 suggests that approximate additive separability Is more Important than distributional assumptions for the small sample performance of both ML and IV estimates. The MLE 1s remarkably robust to non-normality in both examples considered here, and remains efficlent relative to all the IV estimators. ${ }^{12}$ However, In some applications, (e.g., Angrist 1990, Angrist and Krueger 1990a, and the example in this paper) the required micro data are not avallable and the MLE cannot be computed. In such cases an IV estimator that can be computed from second moments offers an attractive and feasible alternative.

6. Summary and Conclusions

Even with valid exclusion restrictions such as generated by the draft lottery, the ab1lity to answer evaluation questions in any field turns on functional form restrictions or distributional assumptions. Th1s paper outlines functional form restrictions necessary and sufficient for 11near IV techniques to provide consistent estimates of average treatment effects. The additive separabllity restrictions required for linear IV estimates to be consistent are unlikely to hold exactly, even for models with continuous outcome variables. But in many circumstances, the restrictions may hold approximately. This point is 11lustrated here using a Monte Carlo study of a bivariate probit model. In a number of examples, IV estimates of the

12 The robustness of ML may be related to Ruud's (1986) result showing that for a large class of regressors, maximum 11 kelihood with a misspecified distribution consistentiy estimates univariate index coefficlents up to scale. 
average treatment effect do not perform appreciably worse than estimates computed using the correct likelihood function.

These results suggest that Inear IV estimation of average treatment effects in nonlinear models can often be justifled, of course. In some applications a varlety of estimation strategles are avallable and all estimation strategies that derive from the same exclusion restrictions should probably be considered. Perhaps the most important reason for presenting IV estimates, however, even when more sophisticated techniques can be used, is that IV techniques are the observational investigator's version of classical experimentation. Instead of an experimenter randomly assigning treatment, the instrumental varlables naturally assign treatment In a manner independent of other characteristics related to outcomes. I belleve this source of Identifying information is easily understood and communicated to non-spectalists, and that findings from simple and comprehensible empirical strategles are most likely to affect public health and social policy. 


\section{SUICIDE AND VETERAN STATUS BY DRAFT-ELIGIBILITY}

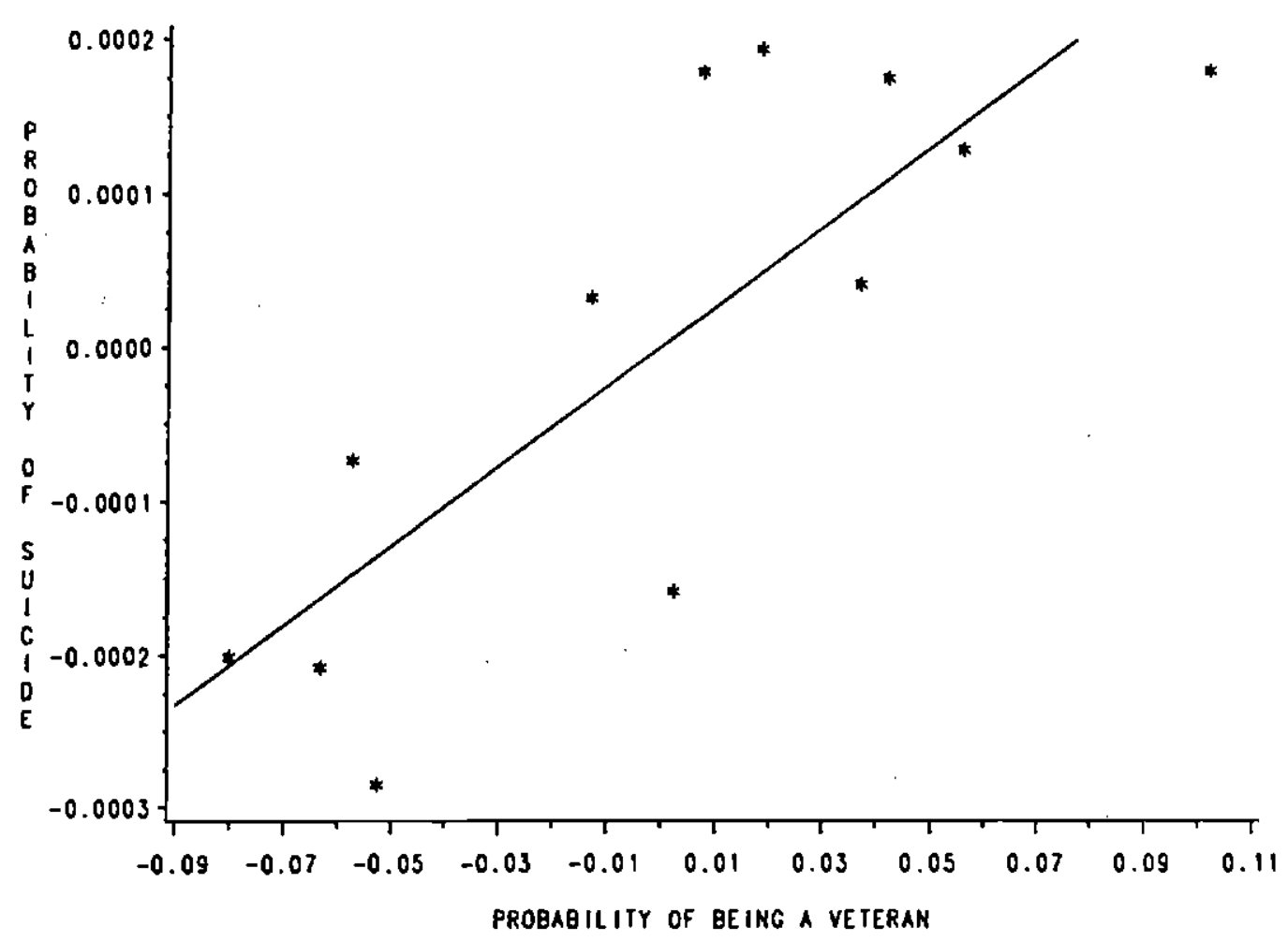

PLOT SHOWS RESIOUALS FROU a REgRESSION ON YEAR AKO RACE EFFECTS SOURCE: CA PA AOUIMISTRATIVE HORYALITY OATA. SIPP VETERAM STATUS OATA

$$
\begin{aligned}
& .0025 \% \\
& (.0000)
\end{aligned}
$$


Table 1: Base Design

\begin{tabular}{|c|c|c|c|c|c|c|c|c|}
\hline Sample & Estimator & $\begin{array}{l}\text { Mean } \\
\text { (1) }\end{array}$ & $\begin{array}{l}\text { SD } \\
(2)\end{array}$ & $\begin{array}{l}\text { RMSE } \\
\text { (3) }\end{array}$ & $\begin{array}{l}\text { MAE } \\
(4)\end{array}$ & $\begin{array}{l}10 \\
(5)\end{array}$ & $\begin{array}{l}\text { MD } \\
(6)\end{array}$ & $\begin{array}{l}\text { UQ } \\
(7)\end{array}$ \\
\hline \multirow[t]{5}{*}{400} & MLE & 11.36 & 10.92 & 11.00 & 8.75 & 3.63 & 11.12 & 18.53 \\
\hline & IV & 12.06 & 11.55 & 11.73 & 9.33 & 4.21 & 11.75 & 19.65 \\
\hline & Dumny IV & 14.13 & 11.15 & 11.89 & 9.40 & 7.12 & 13.80 & 21.70 \\
\hline & Efficient IV & 14.54 & 11.45 & 12.32 & 9.77 & 7.22 & 14.35 & 22.30 \\
\hline & OLS & 38.04 & 4.69 & 28.43 & 28.04 & 34.73 & 38.19 & 41.35 \\
\hline \multirow[t]{5}{*}{800} & MLE & 9.59 & 7.71 & 7.72 & 6.15 & 4.20 & 9.75 & 14.70 \\
\hline & IV & 10.38 & 8.35 & 8.36 & 6.68 & 4.66 & 11.20 & 15.80 \\
\hline & Dummy IV & 11.66 & 8.08 & 8.25 & 6.66 & 6.28 & 12.10 & 16.70 \\
\hline & Efficlent IV & 11.84 & 8.21 & 8.41 & 6.80 & 6.32 & 12.40 & 17.10 \\
\hline & OLS & 37.58 & 3.05 & 27.80 & 27.60 & 35.50 & 37.60 & 39.80 \\
\hline
\end{tabular}

NOTES: The treatment effect consists of a movement from 0.5 to 0.6 . The instrument $\left(Z_{f}\right)$ is discrete, uniformly distributed with 8 points of support in the range $[-3.5,3.5]$. The first stage coefficlents, $\gamma_{0}$ and $\gamma_{1}$, were chosen to generate variation $\operatorname{In} E\left(s_{1} \mid z_{1}\right)$ from 0.2 to 0.8 .

MLE estimates are maximum likelihood estimates for bivariate probit. IV estimates use $Z$ and a constant as instruments. Dummy IV estimates use a full set of dumbies for each value of $Z_{\text {I }}$ as instruments. Efficlent IV estimates uses a full set of dummies in the optimally welghted two-stage least squares estimator. The OLS estimate is the Ordinary Least Squares coefficlent from a regression of $y_{1}$ on $s_{f}$, and is the same as the singleequation problt estimate of the average treatment effect. 
Table 2: Upper To1l Treatment Effect

\begin{tabular}{|c|c|c|c|c|c|c|c|c|}
\hline Sample & Estimator & $\begin{array}{l}\text { Mesn } \\
\text { (1) }\end{array}$ & $\begin{array}{l}S D \\
(2)\end{array}$ & $\begin{array}{l}\text { RMSE } \\
(3)\end{array}$ & $\begin{array}{l}\text { MAE } \\
(4)\end{array}$ & $\begin{array}{l}\text { LQ } \\
(5)\end{array}$ & $\begin{array}{l}M D \\
(6)\end{array}$ & $\begin{array}{l}\text { UQ } \\
(7)\end{array}$ \\
\hline \multirow[t]{5}{*}{400} & MLE & $\begin{array}{c}8.96 \\
(9.12)\end{array}$ & $\begin{array}{c}8.58 \\
(8.75)\end{array}$ & $\begin{array}{c}8.64 \\
(8.79)\end{array}$ & $\begin{array}{c}6.56 \\
(6.66)\end{array}$ & $\begin{array}{c}4.42 \\
(4.26)\end{array}$ & $\begin{array}{c}9.37 \\
(9.89)\end{array}$ & $\begin{array}{c}14.7 \\
(14.9)\end{array}$ \\
\hline & IV & B.8B & B. 16 & B. 24 & 6.47 & 3.38 & 9.07 & 14.1 \\
\hline & Dummy IV & 9.89 & 7.84 & 7.84 & 6.17 & 4.62 & 10.30 & 14.8 \\
\hline & Efficient IV & 9.81 & 8.41 & 8.41 & 6.70 & 4.24 & 10.20 & 15.4 \\
\hline & OLS & 21.3 & 3.25 & 11.80 & 11.30 & 19.10 & 21.20 & 23.6 \\
\hline \multirow[t]{5}{*}{800} & MLE & 9.71 & 5.26 & 5.27 & 4.02 & 6.86 & 10.20 & 13.1 \\
\hline & IV & 8.94 & 5.30 & 5.40 & 4.23 & 5.61 & 9.10 & 12.6 \\
\hline & Dumny IV & 9.49 & 5.22 & 5.24 & 4.12 & 6.26 & 9.49 & 13.0 \\
\hline & Efficient IV & 9.70 & 5.45 & 5.46 & 4.29 & 6.38 & 9.80 & 13.4 \\
\hline & OLS & 21.3 & 2.31 & 11.50 & 11.30 & 19.60 & 21.40 & 22.8 \\
\hline
\end{tabular}

NOTES: The treatment effect consists of a movement from 0.85 to 0.95 . Other design features are as described in Table 1.

In the sample of 400 observations, 23 out of 500 maximum likelihood replications falled to converge. Reported statistics are evaluated for all observations, Including the last completed iteration for nonconvergent estimates. Results for the convergent subsample are reported in parentheses. 
Table 3: Lower Tall piret Stage

\begin{tabular}{|c|c|c|c|c|c|c|c|c|}
\hline Sample & Estimator & $\begin{array}{l}\text { Mean } \\
\text { (1) }\end{array}$ & $\begin{array}{l}\text { SD } \\
\text { (2) }\end{array}$ & $\begin{array}{l}\text { RMSE } \\
(3)\end{array}$ & $\begin{array}{l}\text { MAE } \\
(4)\end{array}$ & $\begin{array}{l}\text { LQ } \\
\text { (5) }\end{array}$ & $\begin{array}{l}\text { MD } \\
(6)\end{array}$ & $\begin{array}{l}\text { UQ } \\
(7)\end{array}$ \\
\hline \multirow[t]{5}{*}{400} & MLE & $\begin{array}{c}11.76 \\
(11.76)\end{array}$ & $\begin{array}{c}21.50 \\
(21.60)\end{array}$ & $\begin{array}{c}21.6 \\
(21.7)\end{array}$ & $\begin{array}{c}17.7 \\
(17.7)\end{array}$ & $\begin{array}{l}-3.50 \\
(-3.50)\end{array}$ & $\begin{array}{l}10.6 \\
(10.6)\end{array}$ & $\begin{array}{c}27.2 \\
(27.2)\end{array}$ \\
\hline & IV & 9.50 & 26.60 & 26.6 & 20.1 & -6.14 & 10.8 & 24.5 \\
\hline & Dummy IV & 15.19 & 22.50 & 23.1 & 17.8 & 2.00 & 15.5 & 29.4 \\
\hline & Efficlent IV & 15.42 & 22.90 & 23.5 & 18.1 & 1.98 & 15.9 & 29.2 \\
\hline & OLS & 40.82 & 5.18 & 31.3 & 30.8 & 37.40 & 40.9 & 44.6 \\
\hline \multirow[t]{5}{*}{800} & MLE & 10.40 & 17.40 & 17.4 & 14.2 & -1.25 & 11.7 & 22.5 \\
\hline & IV & 9.48 & 18.10 & 18.1 & $14: 4$ & -1.97 & 10.5 & 21.0 \\
\hline & Dummy IV & 12.70 & 16.80 & 17.0 & 13.6 & 1.60 & 13.3 & 23.5 \\
\hline & Efficlent IV & 12.80 & 16.90 & 17.1 & 13.7 & 1.60 & 13.6 & 23.9 \\
\hline & OLS & 40.60 & 3.64 & 30.8 & 30.6 & 38.00 & 40.8 & 43.4 \\
\hline
\end{tabular}

NOTES: The treatment effect consists of a movement from 0.5 to 0.6 . The instrument $\left(Z_{f}\right)$ is discrete, uniformly distributed with 8 points of support in the range $[-3.5,3.5]$. The first stage coefficlents, $Y_{0}$ and $\gamma_{1}$, were chosen to generate variation in $E\left(s_{1} \mid z_{1}\right)$ from 0.05 to 0.35 . Other features of the design are as in Table 1 .

In the sample of 400 observations, one out of 500 maximun likelthood replications falled to converge. Reported statistics are evaluated for all observations, Including the last completed iteration for nonconvergent estimates. Results for the convergent subsample are reported In parentheseg. 
Table 4: Opper Ta11 Troatment Effect and Lower Ta11 First stage

\begin{tabular}{|c|c|c|c|c|c|c|c|c|}
\hline Sample & Estimator & $\begin{array}{l}\text { Mean } \\
(1)\end{array}$ & $\begin{array}{l}\text { SD } \\
(2)\end{array}$ & $\begin{array}{l}\text { RMSE } \\
(3)\end{array}$ & $\begin{array}{l}\text { MAE } \\
(4)\end{array}$ & $\begin{array}{l}L Q \\
(5)\end{array}$ & $\begin{array}{l}\text { MD } \\
(6)\end{array}$ & $\begin{array}{l}\text { UQ } \\
(7)\end{array}$ \\
\hline \multirow[t]{5}{*}{400} & MLE & $\begin{array}{c}4.87 \\
(5.42)\end{array}$ & $\begin{array}{c}13.7 \\
(20.9)\end{array}$ & $\begin{array}{c}14.6 \\
(21.4)\end{array}$ & $\begin{array}{r}9.39 \\
(14.4)\end{array}$ & $\begin{array}{c}3.90 \\
(2.69)\end{array}$ & $\begin{array}{r}4.66 \\
(13.6)\end{array}$ & $\begin{array}{r}9.15 \\
(19.4)\end{array}$ \\
\hline & IV & 1.43 & 19.2 & 21.0 & 16.3 & -10.5 & 2.01 & 13.7 \\
\hline & Dummy IV & 4.72 & 16.8 & 17.6 & 13.6 & -5.00 & 5.52 & 15.7 \\
\hline & Efficient IV & 4.31 & 17.3 & 18.2 & 14.3 & -6.88 & 5.26 & 16.2 \\
\hline & OLS & 17.0 & 2.30 & 7.34 & 6.98 & 15.4 & 16.9 & 18.7 \\
\hline \multirow[t]{5}{*}{800} & MLE & $\begin{array}{c}3.97 \\
(3.55)\end{array}$ & $\begin{array}{c}13.8 \\
(18.9)\end{array}$ & $\begin{array}{c}15.1 \\
(20.0)\end{array}$ & $\begin{array}{r}9.60 \\
(13.2)\end{array}$ & $\begin{array}{c}3.96 \\
(0.33)\end{array}$ & $\begin{array}{c}4.62 \\
(10.93)\end{array}$ & $\begin{array}{c}12.1 \\
(16.4)\end{array}$ \\
\hline & IV & 3.67 & 13.5 & 14.9 & 11.7 & -4.51 & 3.62 & 12.0 \\
\hline & Dumny IV & 5.38 & 12.3 & 13.1 & 10.4 & -2.54 & 5.15 & 13.1 \\
\hline & Efflclent IV & 4.76 & 12.8 & 13.8 & 10.9 & -3.01 & 4.73 & 13.3 \\
\hline & OLS & 17.0 & 1.53 & 7.17 & 6.97 & 15.9 & 17.0 & 18.1 \\
\hline
\end{tabular}

NOTES: The treatment effect consists of a movement from 0.85 to 0.95 . The instrument $\left(z_{i}\right)$ is discrete, unlformly distributed with 8 points of support in the range $[-3.5,3.5]$. The first stage coefficients, $\gamma$ and $\gamma_{1}$, were chosen to generate variation in $E\left(s_{1} \mid z_{1}\right)$ from 0.05 to 0.39 . This design combines features of the designs in Tables 2 and 3.

In the samples with 400 observations, only 216 out of 500 maximum 11kel thood replications converged. In the sample with 800 observations. only 266 out of 500 maximum 11 kel hood replications converged. Reported statistics are evaluated for all observations, including the last completed iteration for non-convergent estimates. Results for the convergent subsample are reported in parentheses. 
Table 5: Ch1-8quare Error Diatributione

\begin{tabular}{|c|c|c|c|c|c|c|c|c|}
\hline Sample & Estimator & $\begin{array}{l}\text { Mean } \\
\text { (1) }\end{array}$ & $\begin{array}{l}S D \\
(2)\end{array}$ & $\begin{array}{l}\text { RMSE } \\
\text { (3) }\end{array}$ & $\begin{array}{l}\text { MAE } \\
(4)\end{array}$ & $\begin{array}{l}10 \\
(5)\end{array}$ & $\begin{array}{l}M D \\
(6)\end{array}$ & $\begin{array}{l}\text { UQ } \\
\text { (7) }\end{array}$ \\
\hline \multirow[t]{5}{*}{400} & ML.E & 12.8 & 11.5 & 11.8 & 9.44 & 4.62 & 12.5 & 20.1 \\
\hline & IV & 12.7 & 12.4 & 12.7 & 10.3 & 4.43 & 13.1 & 20.8 \\
\hline & Dumny IV & 15.0 & 11.8 & 12.8 & 10.4 & 6.43 & 14.9 & 23.5 \\
\hline & Efficlent IV & 15.6 & 12.3 & 13.5 & 10.9 & 6.71 & 15.5 & 24.2 \\
\hline & OLS & 39.3 & 4.82 & 29.7 & 29.3 & 36.1 & 39.5 & 42.5 \\
\hline \multirow[t]{5}{*}{800} & MLE & 12.6 & 7.99 & 8.41 & 6.62 & 7.42 & 12.2 & 17.6 \\
\hline & IV & 12.9 & 8.60 & 9.08 & 7.21 & 7.28 & 12.9 & 18.6 \\
\hline & Dummy IV & 14.1 & 8.33 & 9.28 & 7.46 & 8.35 & 14.3 & 19.6 \\
\hline & Efficlent IV & 14.4 & 8.47 & 9.54 & 7.65 & 8.55 & 14.5 & 20.1 \\
\hline & oLs & 39.4 & 3.22 & 29.6 & 29.4 & 37.0 & 39.40 & 41.5 \\
\hline
\end{tabular}

NOTES: The treatment effect consists of a movement from 0.5 to 0.6 . The instrument $\left(z_{f}\right)$ is discrete, uniformly distributed with 8 pqints of support in the range $[1,8]$. All error distributions are $\chi^{2}(1)$, so that the compound errors, $\eta_{11}$ and $\eta_{2}$, are $x^{2}(2)$. The first stage coefficients, $\gamma_{0}$ and $\gamma_{1}$, generate variation in $E\left[s_{1} \mid z_{1}\right]$ from 0.17 to 0.78 . 
Table 6: Unlform/Triangular Error D1stributions

\begin{tabular}{|c|c|c|c|c|c|c|c|c|}
\hline Sample & Estimator & $\begin{array}{l}\text { Mean } \\
(1)\end{array}$ & $\begin{array}{l}\text { SD } \\
(2)\end{array}$ & $\begin{array}{l}\text { RMSE } \\
\text { (3) }\end{array}$ & $\begin{array}{l}\text { MAE } \\
(4)\end{array}$ & $\begin{array}{l}10 \\
(5)\end{array}$ & $\begin{array}{l}\text { MD } \\
(6)\end{array}$ & $\begin{array}{l}\text { UQ } \\
(7)\end{array}$ \\
\hline \multirow[t]{5}{*}{400} & MLE & 8.97 & 11.4 & 11.4 & 9.32 & 4.59 & 7.96 & 16.4 \\
\hline & IV & 9.55 & 12.4 & 12.4 & 10.1 & 5.60 & 9.14 & 18.0 \\
\hline & Dummy IV & 12.2 & 11.5 & 11.7 & 9.47 & 4.39 & 12.6 & 20.0 \\
\hline & Efficient IV & 12.6 & 11.9 & 12.2 & 9.80 & 4.26 & 12.8 & 20.4 \\
\hline & ols & 38.4 & 4.37 & 28.7 & 28.4 & 35.2 & 38.6 & 41.5 \\
\hline \multirow[t]{5}{*}{800} & MLE & 8.91 & 8.18 & 8.25 & 6.64 & 3.07 & 8.69 & 14.3 \\
\hline & IV & 9.88 & 8.99 & 8.99 & 7.18 & 3.85 & 10.2 & 15.6 \\
\hline & Duramy IV & 11.3 & 8.78 & 8.88 & 7.09 & 5.56 & 11.3 & 17.0 \\
\hline & Efflctent IV & 11.5 & 8.91 & 9.04 & 7.22 & 5.54 & 11.5 & 17.1 \\
\hline & OLS & 38.9 & 3.17 & 29.1 & 28.9 & 36.8 & 38.9 & 40.9 \\
\hline
\end{tabular}

NOTES: The treatment effect consists of a movement from 0.4 to 0.5 . The Instrument $\left(z_{1}\right)$ is discrete, uniformly distributed with 8 polnts of support in the range $[1,8]$. All exror distributions are UN $[0,1]$ so that the compound errors, $\eta_{1}$ and $\eta_{21}$, are Triangular on $[0,2]$, with a mode of 1. The first stage coefficlents, $\gamma_{0}$ and $\gamma_{1}$, generate variation in $E\left[s_{1}\left[z_{1}\right]\right.$ from 0.18 to 0.76 . 
Append 1x

Mortallty and Veteran Status by Race, Year of Blrth, and Draft-Eligibllity

\begin{tabular}{|c|c|c|c|c|c|}
\hline Race & Year & $\begin{array}{l}\text { Draft- } \\
\text { Ellglbility }\end{array}$ & $\begin{array}{l}\text { Number of } \\
\text { Deaths } \\
\text { (Sulcides) } b \\
\text { (1) }\end{array}$ & $\begin{array}{l}\text { Probability } \\
\text { of Death } \\
\text { (Sulcide) } \\
\text { (2) }\end{array}$ & $\begin{array}{l}\text { Probability of } \\
\text { Military } \\
\text { Servlce } \\
\text { (3) }\end{array}$ \\
\hline \multirow[t]{3}{*}{ White } & 1950 & $\begin{array}{l}\text { yes } \\
\text { no }\end{array}$ & $\begin{array}{l}2601(436) \\
2169(352)\end{array}$ & $\begin{array}{l}.0204(.0034) \\
.0195(.0032)\end{array}$ & $\begin{array}{l}.3527 \\
.1933\end{array}$ \\
\hline & 1951 & $\begin{array}{l}\text { yes } \\
\text { no }\end{array}$ & $\begin{array}{ll}1494 & (279) \\
2823 & (480)\end{array}$ & $\begin{array}{l}.0170(.0032) \\
.0168(.0029)\end{array}$ & $\begin{array}{l}.2831 \\
.1468\end{array}$ \\
\hline & 1952 & $\begin{array}{l}\text { yes } \\
\text { no }\end{array}$ & $\begin{array}{ll}1079 & (207) \\
2978 & (514)\end{array}$ & $\begin{array}{l}.0154(.0029) \\
.0149(.0026)\end{array}$ & $\begin{array}{l}.2310 \\
.1257\end{array}$ \\
\hline \multirow[t]{3}{*}{ Non-White } & 1950 & $\begin{array}{l}\text { yes } \\
\text { no }\end{array}$ & $\begin{array}{l}536(60) \\
493(46)\end{array}$ & $\begin{array}{l}.0346(.0039) \\
.0365(.0034)\end{array}$ & $\begin{array}{l}.1957 \\
.1354\end{array}$ \\
\hline & 1951 & $\begin{array}{l}\text { yes } \\
\text { no }\end{array}$ & $\begin{array}{l}350(33) \\
612(63)\end{array}$ & $\begin{array}{l}.0376(.0035) \\
.0344(.0035)\end{array}$ & $\begin{array}{l}.2014 \\
.1514\end{array}$ \\
\hline & 1952 & $\begin{array}{l}\text { yes } \\
\text { no }\end{array}$ & $\begin{array}{ll}235 & (26) \\
663 & (66)\end{array}$ & $\begin{array}{l}.0309(.0034) \\
.0309(.0031)\end{array}$ & $\begin{array}{l}.1449 \\
.1287\end{array}$ \\
\hline
\end{tabular}

a Determined by lottery number (RSN) cutoff: RSN 195 for men born in 1950, RSN 125 for men born in 1951, RSN 95 for men born In 1952.

b

From Calffornta and Pennsylvanla administrative records, all deaths 1974-1983. Data sources and methods documented in Hearst, Newman and Hulley (1986).

NOTE: Sample sizes differ from Hearst, et al., because non-US-born are included.

c Equal to number of deaths divided by Population At R1sk (PAR) estimated from the 1970 census, 18 public use sample state flles. PAR is the number of men in each birth cohort and race group. Estlmates of PAR by draft-eliglbility are computed assuming a unform distribution of lottery numbers.

d Relative frequencies estimated from the Survey of Income and Program Participation. Data sources and methods are documented in Angrist (1990).

e Suicide 1s ICD 950-959.9. Total sulcides - 2268 whites, 294 non-whites. 
Angrist, J.D. (1990). "Lifetime Earnings and the Vietnam Era Draft Lottery: Evidence from Social Security Administrative Records, "American Economic Review, June 1990.

(1991), "Grouped Data Estimation and Testing In Simple Labor Supply Mode1s," Journal of Econometrics 47, 243-266.

, and Alan Krueger (1989), "Why Do World War Two Veterans Earn More than Nonveterans?," NBER Work1ng Paper.

, and Alan Krueger (1990a). "The Effect of Age at School Entry on Educational Attainment: An Application of Instrumental Varlables with Moments from Two Samples," Harvard Institute of Economic Research Discussion paper No. 1475, March.

, and (1991), "Does Compulsory School Attendance Affect Schooling and Earnings?," Quarterly Journal of Economics, November.

Anemiya, T. (1974), "Bivarlate Prob1t Analysis: Minimum Chi-Square Methods," Journal of the American Statistical Association 69: 940-944.

(1978), "The Estimation of a Simultaneous Equation Generalized Prob1t Mode1," Econometrica 46: 1193-205.

Ashford, J.R., and R.R. Snowden (1970), "Multivariate Prob1t Analys1s," Blometr1cs 26: 535-646.

(1987), "Asymptotic Efficiency in Estimation with Conditional Moment Restrictions," Journal of Econometrics 34: 305-334.

Ham, J.C. and R.J. LaLonde (1990), "Using Social Experiments to Estimate the Effect of Training on Transition Rates, " In Panel Data and Labor Market Studies, edited by J. Hartog, G. Ridder, and J. Theeuwes, Amsterdam: NorthHolland.

Hearst, N., T. Newman and S.B. Hulley (1986), "Delayed Effects of the Military Draft on Mortality: A Randomized Natural Experiment," New England Journal of Medicine 314 (March 6, 1986): 620-624.

Hearst, N., J. W. Buehler, T. Newman, and G.W. Rutherford (1990), "The Draft Lottery and AIDS: Evidence Against Increased Intravenous Drug Use by Vietnam-era Veterans," Mimeo, Department of Epidemiology and Blostatistics, University of California, San Francisco, March.

Heckman, J.J. (1978), "Dummy Endogenous Variables in a Simultaneous Equations System," Econometrica 46(6): 931-959.

$80(2): 313-318$

(1990), "Varieties of Selection Bias," Anerican Economic Review 
and RIchard Robb (1985), "Alternatlve Methods for Evaluating the Impact of Interventlons, " In Heckman and SInger, eds.. Longltudinal Analys $1 s$ of Labor Market Data, New York: Cambridge UnIversity Press.

Kelejlan, H. (1971), "Two-Stage Least Squares and Econometrlc Systems LInear in Parameters but Nonlinear in the Endogenous Varlables," Journal of the Amerlcan Statistical Association 66: 373-374.

Lalonde, R.J. (1986), " Evaluating the Econometrlc Evaluations of Training Programs Using Experimental Data,- Amertcan Economlc Revlew 76(4): 602-620.

Maddala, G.S. (1983), LImlted Dependent and Oualltatlve Varlables in Econometrlcs, New York: Cambrldge University Press.

Mansk1, C. (1975), "Maximum Score Estimation of the Stochastic Ut1lity Model of Cholce," Journal of Econometrics 3: 205-228.

McFadden, D., and F. Reld (1975), "Aggregate Travel Demand Forecasting from Dlsaggregated Behavioral Models," Transportation Research Board Record No. 534: 24-37.

Nelson, C.R., and R. Startz (1990), "Some Further Results on the Exact Small Sample Properties of the Instrumental Varlables Estlmator," Econometrica 58(4): 967-976.

Newey, Whitney K. (1985a), "Semlparametrlc Estlmatlon of LImlted Dependent Varlable Models with Endogenous Explanatory Varlables," Annales De L'INSEE $59 / 60: 219-235$.

(1985b), "Generallzed Method of Moments Estimation and Testing." Journal of Econometrles 29: 229-256.

(1986), "LInear Instrumental Varlables Estimation of LImIted Dependent Varlable Models with Endogenous Explanatory Varlables," Journal of Econometrles 32: $127-141$.

(1987), "Efflclent Estimation of Limlted Dependent Varlables with Endogenous Explanatory Varlables," Journal of Econometrics 36: 231 250 .

(1989), "Efflclent Instrumental Varlables Estimation of Nonlinear Models," Princeton Unlversity Econometrlc Research Program Memorandum No. 341, March 1989.

Permutt, Thomas and J. Rlchard Hebel (1989), "Simultaneous-Equation Estimation in a Clinical Trial of the Effect of Smoking on Birth Weight," Biometrles 45 (June): 619-622.

Roblns, James M. (1989), "The Analys is of Randomlzed and Non-Randomlzed AIDS Treatment Trlals Using a New Approach to Causal Inference in Longltudinal studles," Health Servlce Research Methodology: A Focus on AIDS, edlted by L. Sechrest, H. Freeman, and A. Balley, NCHSR, U.S. Public Health Service. 
Rosenbaum, P.R. and D.B. Rubin (1983), "Assessing Sensitivity to an Unobserved Binary Covarlate in an Observational Study with Binary Outcome," Journal of the Royel Statigtical Soclety Serles B 45(2): $212-218$.

Rubin, D. (1974), "Estimating Causal Effects of Treatments in Randomized and Non-randomized Studies," Journal of Educational Psychology 66(5): 688701.

Ruud, Paul (1986), "Consistent Estimation of LImited Dependent Varlables Models Despite Misspecification of Distribution," Journal of Econometrics 32: $157-187$.

Seltzer, C.C. and S. Jablon (1974). "Effects of Selection on Mortality," American Journal of Epidemiology 100:367-372.

Stoker, T.M. (1986), "Consistent Estimation of Scaled Coefficients," Econometrica 54(6): $1461-1481$.

White, H. (1982), "Instrumental Varlables Regression with Independent Observations," Econometrica 50: 482-499. 